\title{
PENERAPAN TERAPI PERILAKU:TOKEN EKONOMI PADA KLIEN DENGAN GANGGUAN SENSORI PERSEPSIHALUSINASI DENGAN PENDEKATAN HEALTH BELIEF MODEL
}

Studi Pada Klien Di RSJ Dr.Radjimanwediodiningrat Lawang

\author{
Ari Damayanti W \\ Prodi Ilmu Keperawatan STIKES Widyagama Husada \\ alizadamayanti@gmail.com
}

\begin{abstract}
Mental disorders are varied-multi-causal diseases. Clients with mental disorders experienced many cog nitive distortions that indirectly lead behavioral disorders that are caused by the use of logic error, wrong reasoning, inappropriate way of thinking to the reality, unawareness of divergent behavior, and inability of making relationship with others. These lead to the harmful hallucination that endangers the clients themselves, other people and the surroundings. Hallucination is a perception disorder where what the client thinks contradicts what really happens. Behavioral therapy is reeducation that modifies the behavior of the clients to be more favorable based on the systematic positive reinforcement in the target behavior. The tokens can be exchanged to get something to be desired and expected. The purpose of the study was to identify and analyze the application of behavior therapy: a token economy on clients with sensory perception disorder: hallucinations in Dr.Radjiman Wediodiningrat Lawang Mental Hospital. The Pretest-Posttest without control $g$ roup was applied to be the design in this study involving 40 respondents as the sample and using consecutive sampling method. The behavioral therapies variables were the token economy and the ability to control hallucinations. The data were analyzed using the Wilcoxon Sign Rank Test with the results of $\rho=0.000<0.05$ which meant that there was a significant difference between the hallucination category before and after the treatment. In conclusion, the provision of behavioral therapy treatment: the token economy with health belief models theory can change the client's behavior adaptively so that the client can control the hallucinations. The suggestion of this study is nurses should be able to apply the behavioral therapy: the token economy on the other case besides hallucinations.
\end{abstract}

Keywords: Token Economy, Disorders of Perception: Hallucinations, Health Belief Models Theory 


\section{Abstrak}

Gangguan jiwa merupakan penyakit multi kausal bervariasi. Klien gangguan jiwa banyak mengalami distorsi kognitif yang akhirnya mengarah ke gangguan perilaku. Hal tersebut disebabkan oleh kesalahan logika, kekeliruan penggunaan alasan atau pandangan individu yang tidak sesuai dengan kenyataan, tidak merasa memiliki perilaku menyimpang, tidak bisa membina hubungan relasi dengan orang lain. Gangguan halusinasi mengarah pada perilaku membahayakan orang lain, klien sendiri dan lingkungan sekitar. Halusinasi merupakan gangguan persepsi dimana klien mempersepsikan sesuatu yang lain yang sebenarnya tidak terjadi. Terapi perilaku bersifat reedukasi yang memodifikasi perilaku klien dengan perilaku lain yang lebih menguntungkan didasarkan pada sistematik reinforcement positif pada target perilaku. Token-token dapat ditukar untuk mendapatkan sesuatu yang diinginkan dan dinikmati. Tujuan penelitian ini adalah untuk mengidentifikasi dan menganalisis penerapan terapi perilaku: token ekonomi pada klien dengan gangguan sensori persepsi: halusinasi di Rumah Sakit Jiwa Dr.Radjiman Wediodiningrat Lawang. Desain yang digunakan dalam penelitian ini adalah Pre dan Post Test tanpa Control Group yang melibatkan 40 responden dengan metode pengambilan consecutive sampling. Variabel penelitian meliputi terapi perilaku: token ekonomi dan kemampuan mengendalikan halusinasi. Sedangkan alat ukur yang digunakan adalah lembar observasi dan wawancara. Data yang diperoleh dianalisis dengan menggunakan uji Wilcoxon Sign Rank Test dengan hasil $\mathrm{Q}=0,000<0,05$ yang artinya ada perbedaan kategori halusinasi yang signifikan sebelum dan sesudah perlakuan. Kesimpulan dari penelitian ini adalah bahwa pemberian perlakuan terapi perilaku: token ekonomi dengan pendekatan teori Health Belief Model dapat mengubah perilaku klien ke arah adaptif sehingga klien dapat mengontrol halusinasi. Berdasarkan hasil penelitian, disaran kepada para perawat utuk dapat mengaplikasikan terapi perilaku : token ekonomi pada kasus selain halusinasi.

\section{Keywords: Terapi Perilaku, Token Ekonomi, Gangguan Persepsi, Halusinasi, Teori} Health Belief Model

\section{PENDAHULUAN}

Krisis multi dimensi menyebabkan tekanan pada sebagian besar masyarakat dunia, khususnya Indonesia. Masyarakat yang mengalami krisis ekonomi tidak saja mengalami gangguan kesehatan fisik berupa gangguan gizi, terserang berbagai penyakit, tapi juga mengalami gangguan kesehatan jiwa, sehingga menurunkan produktifitas kerja dan kualitas hidup secara nasional.

Gangguan jiwa merupakan penyakit multi kausal bervariasi. Klien gangguan jiwa banyak mengalami distorsi kognitif yang akhirnya mengarah pada gangguan perilaku, hal tersebut disebabkan oleh kesalahan logika, kekeliruan penggunaan alasan atau pandangan individu yang tidak sesuai dengan kenyataan (Stuart, 2009). Kesalahan logika menyebabkan klien gangguan jiwa mempunyai pemikiran sempit tentang sesuatu hal, termasuk tentang dirinya. Mereka tidak merasa memiliki perilaku menyimpang dan tidak dapat membina hubungan relasi dengan orang lain (Yosep, 2010).

Skizofrenia merupakan sindrom disebabkan oleh bermacam-macam penyebab ditandai dengan penyimpangan pikiran dan persepsi serta efek tidak wajar. Berdasarkan data WHO (2001) diperkirakan 450 juta orang menderita gangguan mental, neurologis maupun masalah psikososial termasuk kecanduan alkohol dan penyalahgunaan obat, 121 juta orang mengalami depresi dan 50 juta 
orang mengalami epilepsi, 24 juta orang mengalami skizofrenia.

Berdasarkan hasil Riset Kesehatan dasar (Riskesdas) 2007 jumlah penduduk Indonesia sebanyak 200 juta jiwa, jumlah penderita skizofrenia diperkirakan sebesar $1 \%$ dari jumlah penduduk yaitu 2 juta jiwa. Prevalensi gangguan jiwa berat (skizofrenia) di Indonesia 0,46\% dengan prevalensi tertinggi DKI Jakarta 2.03\%, Nanggro Aceh Darussalam 1.85\%, Sumatera Barat $1.67 \%$, Nusa Tenggara Barat $0.99 \%$. Sedangkan prevalensi gangguan jiwa di Jawa Timur $1.4 \%$, dan Malang 29.6\%.

Diperkirakan lebih dari $90 \%$ pasien skizofrenia mengalami halusinasi. Gangguan persepsi sensori: halusinasi merupakan salah satu masalah keperawatan yang perlu mendapat perhatian dan penanganan tepat dari perawat. Gangguan halusinasi mengarah pada perilaku membahayakan orang lain, klien sendiri dan lingkungan sekitar. Halusinasi merupakan gangguan persepsi

Token ekonomi didasarkan pada operant conditioning. Conditioned reinforcer dalam bentuk token diberikan pada pasien yang memunculkan respon yang diinginkan. Token-token ini nantinya dapat ditukar untuk mendapatkan primary reinforce yaitu sesuatu yang diinginkan dan dinikmati. Token ekonomi digunakan Tujuan keperawatan adalah untuk pengembangan kepribadian kearah pribadi dan kehidupan yang konstruktif, kreatif, dan produktif (Stuart \& Laria, 2006). Penerapan terapi perilaku : token ekonomi pada klien halusinasi dengan pendekatan health belief model bertujuan agar klien berhasil mengendalikan halusinasinya.

\section{METODE PENELITIAN}

Desain penelitian dalam penelitian ini adalah Pre dan Post Test tanpa Control Group. Penelitian dilaksanakan di Rumah Sakit Jiwa Dr.Radjiman Wediodiningrat, dimana klien mempersepsikan sesuatu yang lain sebernarnya tidak terjadi. Suatu pencerapan panca indra tanpa ada rangsangan dari luar (Maramis, 1998). Suatu penghayatan yang dialami seperti suatu persepsi melalui panca indera tanpa stimulus eksteren, persepsi palsu (Stuart \& Laria, 2006).

Tindakan non farmakologis yang dilakukan klien halusinasi diantaranya terapi modalitas melalui terapi perilaku (Stuart \& Laria, 2006). Terapi perilaku bersifat reedukasi yang memodifikasi perilaku klien dengan perilaku lain yang lebih menguntungkan, misalnya perilaku menuruti halusinasi dimodifikasi dengan menentang halusinasi. Terapi perilaku dapat dikombinasikan dengan teknik lain untuk meningkatkan partisipasi klien dalam mengendalikan halusinasinya (Saunders, 2009).

Token ekonomi adalah suatu modifikasi sistem perilaku yang didasarkan pada sistematik reinforcement positif pada target perilaku.

untuk menghasilkan perubahan positif (Stuart \& Laria, 2006). Pelaksanaan token ekonomi meliputi identifikasi kemampuan interpersonal positif dan perilaku self care yang dikuatkan dan mendapatkan dispensasi berupa tanda pada klien apabila kemampuannya meningkat.

untuk mengumpulkan data menggunakan lembar observasi dan wawancara dengan melakukan anamnesa dengan pengkajian sebelum responden diberikan terapi perilaku untuk mengetahui fase halusinasi kemudian memberikan perlakuan dengan menggunakan terapi perilaku dengan memberikan token ekonomi (kepingan) bagi responden yang menunjukkan perilaku adaptif kemudian token tersebut dapat ditukarkan dengan reward berupa makanan dan barang untuk responden.Hasil penyajian data penelitian sebelum dan sesudah perlakuan 
dijelaskan menggunakan tabel tabulasi

distribusi frekuensi dibawah ini.

\section{HASIL PENELITIAN}

Tabel 1. Distribusi responden berdasarkan umur

\begin{tabular}{|c|c|c|c|}
\hline \multirow[t]{2}{*}{ No } & \multirow[t]{2}{*}{ Umur Dewasa } & \multicolumn{2}{|c|}{$\begin{array}{l}\text { Kelompok } \\
\text { Perlakuan }\end{array}$} \\
\hline & & $\mathrm{N}$ & $\%$ \\
\hline 1 & 20-29 tahun & 3 & 7,5 \\
\hline 2 & 30-39 tahun & 24 & 60 \\
\hline 3 & 40-49 tahun & 13 & 32,5 \\
\hline & Total & 40 & 100 \\
\hline & $\begin{array}{l}\text { Tabel } 1 \text { diat } \\
\text { an besar umu } \\
\text { stage dewasa } \\
\text { sebanyak } 24 \text { res }\end{array}$ & $\begin{array}{l}\text { men } \\
\text { spon } \\
\text { lya } \\
\text { len }(\end{array}$ & $\begin{array}{r}\text { barkan } \\
\text { berada } \\
30-39\end{array}$ \\
\hline
\end{tabular}

Tabel 2. Distribusi responden berdasarkan jenis halusinasi

\begin{tabular}{clcc}
\hline No & Jenis Halusinasi & \multicolumn{2}{c}{$\begin{array}{c}\text { Kelompok } \\
\text { Perlakuan }\end{array}$} \\
\cline { 3 - 4 } & & $\mathrm{n}$ & $\%$ \\
\hline 1 & Pendengaran & 20 & 50 \\
\hline 2 & Penglihatan & 14 & 35 \\
\hline 3 & Perabaan & 6 & 15 \\
\hline \multicolumn{2}{l}{ Total } & 40 & 100 \\
\hline
\end{tabular}

Tabel 2 menggambarkan sebagian besar responden mengalami jenis halusinasi pendengaran sebanyak 20 responden $(50 \%)$.

Tabel 3. Distribusi responden berdasarkan Kategori halusinasi sebelum dan sesudah diberikan perlakuan

\begin{tabular}{|c|c|c|c|c|c|}
\hline \multirow[t]{2}{*}{ No } & \multirow[t]{2}{*}{$\begin{array}{c}\text { Kategori } \\
\text { Halusinasi }\end{array}$} & \multicolumn{2}{|c|}{$\begin{array}{l}\text { Sebelum } \\
\text { Perlakuan }\end{array}$} & \multicolumn{2}{|c|}{$\begin{array}{l}\text { Sesudah } \\
\text { Perlakuan }\end{array}$} \\
\hline & & $\mathrm{n}$ & $\%$ & $\mathrm{n}$ & $\%$ \\
\hline 1 & $\begin{array}{c}\text { Dapat } \\
\text { mengontrol } \\
\text { halusinasi }\end{array}$ & 0 & 0 & 36 & 90 \\
\hline 2 & $\begin{array}{c}\text { Cemas ringan } \\
\text { (fase I) }\end{array}$ & 17 & 42,5 & 4 & 10 \\
\hline 3 & $\begin{array}{c}\text { Cemas sedang } \\
\text { (fase II) }\end{array}$ & 23 & 57,5 & 0 & 0 \\
\hline & Total & 40 & 100 & 40 & 100 \\
\hline & $\begin{array}{l}\text { oxon Sign Rank } \\
\text { Test }\end{array}$ & \multicolumn{4}{|c|}{$p=0,000$} \\
\hline
\end{tabular}

Tabel 3. menggambarkan hasil analisis Wilcoxon pada kelompok perlakuan diperoleh nilai $\mathrm{p}=0,000<0,05$ artinya ada perbedaan kategori halusinasi yang signifikan saat pre tes dan post tes.

\section{PEMBAHASAN}

\section{Karakteristik Responden}

Berdasarkan hasil penelitian pada tabel 1 sebagian besar responden terkategori berumur dewasa madya (dewasa pertengahan) sebanyak 24 responden $(60 \%)$ Masa ini adalah masa seseorang untuk memperluas keterlibatan dan tanggung jawab pribadi dan sosial seperti membantu generasi berikutnya menjadi individu yang berkompeten, mencapai dan mempertahankan kepuasan dalam berkarir.

Pada masa dewasa pertengahan seseorang mempunyai tugas perkembangan seperti memperoleh tanggung jawab sosial, membangun dan mempertahankan standar ekonomi, membantu anak remaja untuk menjadi orang dewasa yang bertanggung jawab, membina hubungan dengan pasangan hidup dan sebagainya. Akan tetapi jika dalam masa dewasa madya mengalami konflik dapat menjadi salah satu faktor predisposisi terjadinya gangguan jiwa. Menurut Stuart (2007) gangguan kepribadian schizophrenia dapat terjadi pada hampir setiap tingkat usia, yang paling banyak terjadi pada rentang usia 3039 tahun dapat mencapai $65 \%$.

Berdasarkan tabel 2 sebagian besar responden mengalami halusinasi jenis pendengaran sebanyak 20 responden $(50 \%)$ menurut Stuart (2007) bahwa halusinasi pendengaran (audiotorik) merupakan bentuk yang paling sering dari gangguan persepsi pada klien dengan gangguan jiwa (schizoprenia) sebanyak 70\%.

Bentuk halusinasi ini dapat berupa suara-suara bising atau mendengung, akan 
tetapi paling sering berupa kata-kata yang tersusun dalam bentuk kalimat yang mempengaruhi tingkah laku klien, sehingga klien menghasilkan respon tertentu seperti : bicara sendiri, bertengkar atau respon lain yang membahayakan.

Dapat juga klien bersikap mendengarkan suara halusinasi tersebut dengan mendengarkan penuh perhatian pada orang lain yang tidak bicara atau pada benda mati. Halusinasi pendengaran merupakan suatu tanda mayor dari gangguan schizoprenia dan satu syarat diagnostik minor psikosa mania depresif dan syndroma otak organik.

\section{Kategori halusinasi Sebelum dan Sesudah Pemberian Terapi Perilaku:Token Ekonomi dengan Pendekatan Teori}

\section{Health Belief Model}

Berdasarkan tabel 3 sebelum dilakukan perlakuan berupa pemberian terapi perilaku sebagian besar responden mengalami cemas sedang (fase II) sebanyak 23 responden (57,5\%). Respon klien terhadap halusinasi dapat berupa curiga, ketakutan, perasaan tidak aman, gelisah dan bingung, prilaku merusak diri, kurang perhatian, tidak mampu mengambil keputusan serta tidak dapat membedakan keadaan nyata dan tidak nyata. Perasaan cemas yang berlebihan atas dasar problem yang tidak dapat diatasi merupakan penyebab halusinasi terjadi. Isi dari halusinasi dapat berupa perintah memaksa dan menakutkan. Klien tidak sanggup lagi menentang perintah tersebut hingga dengan kondisi tersebut klien melakukan sesuatu terhadap ketakutan tersebut.

Tanda dan gejala dari fase II halusinasi antara lain pengalaman sensori menjijikkan dan menakutkan, klien mulai lepas kendali dan kemungkinan mencoba untuk mengambil jarak dirinya dengan sumber yang dipersepsikan, terjadi peningkatan tanda-tanda sistem saraf otonom akibat ansietas seperti peningkatan tanda-tanda vital (denyut jantung, pernapasan dan tekanan darah), asyik dengan pengalaman sensori dan kehilangan kemampuan untuk membedakan halusinasi dengan realita.

Setelah diberikan perlakuan sebagian besar responden menunjukkan perubahan perilaku dapat mengontrol halusinasi sebanyak 36 responden (90\%) hal ini menunjukkan bahwa tingkah laku manusia dapat diubah dengan menggunakan berbagai pendekatan dan teknik.

Teknik yang dapat digunakan untuk perubahan tingkah laku klien salah satunya token ekonomi. Menurut Miltenberger (2001), token ekonomi dianggap efektif karena token yang diberikan kepada klien merupakan bentuk hadiah bagi peningkatan tingkah laku yang disukai (perilaku adaptif) dan pengurangan tingkah laku yang tidak disukai (perilaku maladaptif).

Tujuan diterapkannya token ekonomi adalah untuk mengajarkan tingkah laku yang tepat dan keterampilan sosial yang dapat dipergunakan dalam suatu lingkungan alamiah.

Health belief model adalah bentuk penjabaran dari model sosio-psikologis. Munculnya model ini didasarkan pada kenyataan bahwa problem kesehatan ditandai kegagalan orang atau masyarakat untuk menerima usaha pencegahan dan penyembuhan penyakit yang diselenggarakan provider (Notoatmodjo, 2010). Health belief model dikembangkan untuk mengubah perilaku agar lebih baik lagi dalam mengubah perilaku dan kebiasan tidak sehat menjadi perilaku yang sehat.

\section{PENUTUP}

\section{Kesimpulan}

perilaku : token ekonomi dengan pendekatan teori health belief model dapat mengubah prilaku klien ke arah adaptif 
sehingga klien dapat mengontrol halusinasi.

\section{Saran}

Berdasarkan hasil penelitian yang dilakukan, perawat diharapkan untuk dapat mengaplikasikan terapi perilaku : token ekonomi pada kasus selain halusinasi.

\section{DAFTAR PUSTAKA}

Alligood \& Tomey. 2002. Nursing Teori and

Their Work. Mosby Elsevier. Philadelphia.

Azwar. 2001. Metode Penelitian. Yogyakarta:Pustaka Pelajar.

Dharma, Kelana. 2011. Metodologi Penelitian Keperawatan Panduan Melaksanakan dan Menerapkan Hasil Penelitian. Jakarta: Trans Info Media.

Glandz, Riner \& Lewis. 2003. Health Behavior and Health Education: Theory, Research and Practice. 3ed. San Fransisco: Josey-Bass Publisher.

Keliat, Budi Ana. 2006. Proses Keperawatan Kesehatan Jiwa. Jakarta: EGC

Maramis, W.F. 2004. Catatan Ilmu Kedokteran Jiwa. Surabaya: Airlangga University Press.

Miltenberger. 2001.Behavior Modification: Principles and Procedures. 2nd ed.Belmont, California: Wadsworth/Thomson Learning

Notoatmodjo, S. 2010. Ilmu Perilaku Kesehatan. Jakarta: Rineka Cipta.

Rasmun. 2001. Keperawatan Kesehatan Mental Psikiatrik Terintegrasi Dengan Keluarga $a_{\llcorner}$Edisi I. Jakarta: CV. Sagung Seto.

Riskesdas. 2007. Laporan Hasil Riset Kesehatan Dasar Nasional, Badan
Penelitian dan Pengembangan Kesehatan Departemen Kesehatan Republik Indonesia, Jakarta.

Rosyid. 2010. Konsep Modul. Website: (http://www.rosyid.info/2010/06/ pengertian- fungsi-dan-tujuanpenulisan.html). Diakses pada 18 Januari 2014.

Stuart, G.W. \& Saunders. 2009. Principles and Practice of Psychiatric Nursing, $9^{\text {th }}$ Edition. St. Louise: Mosby.

Stuart, G.W \& Sundeen, S.J. 2007. Buku Saku Keperawatan Jiwa (Terjemahan). Jakarta: EGC. 